\title{
The Relationship between Vitamin D Deficiency and Pulmonary Hypertension
}

\author{
Demir M. ${ }^{1}$, Uyan U. ${ }^{2}$, Keçeoçlu S. ${ }^{1}$, Demir C. ${ }^{3}$ \\ ${ }^{1}$ Department of Cardiology, Bursa Yüksek İhtisas Education and Research Hospital, \\ Bursa, Turkey; \\ 2Department of Cardiology, Tokat Zile State Hospital, Tokat, Turkey; \\ ${ }^{3}$ Department of Infectious, Bursa Șevket Yılmaz Education and Research Hospital, \\ Bursa, Turkey \\ Received April 15, 2013; Accepted August 14, 2013.
}

Key words: Vitamin D - Pulmonary artery pressure - Renin-angiotensinaldosterone system

\begin{abstract}
Vitamin D deficiency actives renin-angiotensin-aldosterone system (RAAS) which affects cardiovascular system. Activation of RAAS is associated with pulmonary hypertension (PHT). Relation between vitamin D deficiency and PHT could be therefore suggested. In our study we compared pulmonary artery pressure between vitamin $D$ deficiency and control groups. 115 consecutive patients (average age: $61.86 \pm 5.86$ ) who have detected very low vitamin $D$ (vitamin $D$ levels $<10 \mathrm{ng} / \mathrm{ml}$ ) were enrolled. 117 age matched persons (average age: $61.74 \pm 5.99)$ were selected as the control group. All groups underwent transthoracic echocardiography. Routine biochemical measurement of $25-\mathrm{OH}$ vitamin D and parathormon (PTH) levels were performed. Baseline characteristics of the study groups were comparable. Systolic pulmonary artery pressure (SPAP) of patients in the low vitamin D group was higher than the control groups. As a result our study, a relation between vitamin $D$ deficiency and pulmonary artery hypertension was revealed.
\end{abstract}

Mailing Address: Mehmet Demir, MD., Department of Cardiology, Bursa Yüksek İhtisas Education and Research Hospital, Prof Tezok Cd. 16250, Yıldırım, Bursa, Turkey; Phone: +902 243605 050; e-mail: drmehmetdemir@hotmail.com 


\section{Introduction}

The Centers for Disease Control and Prevention have reported that the percentage of adults achieving vitamin $\mathrm{D}$ sufficiency as defined by 25 -hydroxyvitamin $(25-(\mathrm{OH})) \mathrm{D}$ of at least $30 \mathrm{ng} / \mathrm{ml}$ has declined from about $60 \%$ in 1988-1994 to approximately $30 \%$ in $2001-2004$ in whites and from about $10 \%$ to approximately $5 \%$ in African Americans during this same time (Ginde et al., 2009). Recent studies have revealed the functions of vitamin $D$ other than those in bone metabolism. It was reported that it is involved in autoimmune disorders, such as inflammatory bowel disease, rheumatoid arthritis, multiple sclerosis, psoriasis, diabetes, certain cancer types, hypertension, heart failure, atherosclerosis, peripheral artery disease, and in several infectious diseases. Vitamin D deficiency can play a role in the development of cardiovascular conditions such as coronary artery disease, heart failure and hypertension (DeLuca, 2004). Vitamin D deficiency activates renin-angiotensin-aldosterone system (RAAS) which affects the cardiovascular system and can bring hypertension. Vitamin $D$ directly affects the proliferation of the vascular smooth muscle cells and the expression of vascular endothelial growth factor (VEGF) and endotheline via vitamin D receptor (VDR) in cardiomyocytes, vascular smooth muscle cells and in endothelial cells

(Cardús et al., 2006).

Pulmonary vascular alterations such as vasoconstriction, endothelial and smooth muscle cell proliferation, thrombosis and inflammation result in sustained elevated pulmonary vascular resistance and pulmonary remodelling by RAAS are main pathogenetic mechanisms of pulmonary hypertension (PHT) (Humbert et al., 2004; Simonneau et al., 2004). For this reason, it could be suggested that a relation exists between vitamin $\mathrm{D}$ deficiency and PHT.

As far as we know, up to now, no study has been performed on the relationship between vitamin D deficiency and PHT. In our study, we compared systolic pulmonary artery pressure (PAP) between patients who have vitamin $D$ deficiency and control groups.

\section{Material and Methods}

Selection of the patients

115 consecutive patients who appealed to the cardiology and infectious disease outpatient clinic (average age: $61.86 \pm 5.86$ ) with very low vitamin $D$ level $(<10 \mathrm{ng} / \mathrm{ml}$ ) were enrolled. 117 age matched persons (average age: $61.74 \pm 5.99$ ) were selected as the control group. Since the level of $25-\mathrm{OH}$ vitamin $\mathrm{D}$ differs due to seasonal changes (effect of the sunlight), the study started in the winter season and continued up to the end of March. In our study we compared pulmonary artery pressure between vitamin $D$ deficiency group and control group.

Entry criteria included patients with very low vitamin $D$ status and age between $40-70$ years. 
The exclusion criteria

Patients with chronic renal failure, chronic liver disease, cardiac failure (ejection fraction below 50\%), coronary artery disease, congenital heart disease, moderatesevere valvular disease, obstructive sleep apnea and chronic obstructive pulmonary disease, stroke, diabetes mellitus, hypertension, bone disorders, thyroid disorder, previous gastrectomy or having intestinal malabsorption and taking medication may have an effect on vitamin D or parathyroid hormone (PTH) level such as calcium, vitamin $D$ or anti-depressant drugs were excluded from the study. The study did not include male and female patients younger than 40 years or older than 70 years.

The blood pressure of the patients was measured in the both upper limb of the patient while the patient was seated, after a 5-minute rest at office for once. Patients with systolic blood pressure $\geq 140 \mathrm{~mm} \mathrm{Hg}$ and/or diastolic blood pressure $\geq 90 \mathrm{~mm} \mathrm{Hg}$ and those taking antihypertensive drugs were deemed to be hypertensive. The patients using oral antidiabetic drugs or insulin or those having two measurements of fasting blood glucose level $\geq 126 \mathrm{mg} / \mathrm{dl}$ were deemed to be diabetic.

\section{Laboratory tests}

Fasting blood glucose, serum creatinine, total cholesterol, electrolytes and TSH (thyroid stimulating hormone) levels were recorded. Blood samples were drawn by venipuncture to perform routine blood chemistry.

Serum PTH measurements were performed using the electrochemiluminescence method on E 170 Modular Analytic System (Roche, USA) device.

25-hydroxyvitamin D levels were measured using BioSource $25 \mathrm{OH}$-Vit. D3-Ria-CT Kit (BioSource Europe S.A., Rue de L'Industrie, 8, B-1400 Nivelles, Belgium). The reference ranges of $25-\mathrm{OH}-\mathrm{D} 3$ was accepted as $10-50 \mathrm{ng} / \mathrm{ml}$ for the winter season and $20-120 \mathrm{ng} / \mathrm{ml}$ for the summer season (Bischoff-Ferrari et al., 2006).

\section{Transthoracic echocardiography protocol}

Echocardiographic evaluations were performed on Vivid 7 Pro TTE with $3.5 \mathrm{MHz}$ transducer. All echocardiographic images were recorded while patient were lying in a lateral decubitus position. On echocardiographic evaluation, the dimensions of the left ventricle (LV) chamber, wall thickness, the LV ejection fraction (with Teichholz method), the diameter of the left atrium, abnormal blood flows due to valve insufficiency and, if present, the degree of valvular stenosis were evaluated with 2D, M-mode, Doppler and tissue Doppler studies (Lang et al., 2006).

Parasternal long axis, apical two-, four- and five-chamber views were taken. Thicknesses of the LV septal and posterior-free walls and LV end-diastolic and end-systolic diameters were measured in parasternal long-axis view with M-mode.

Systolic pulmonary artery pressure (PAP) was calculated by adding the estimated right atrial pressure (RAP) to the right ventricle systolic pressure obtained from 
the tricuspid insufficiency peak velocity (TRmax) according to Bernoulli equation (systolic PAP = 4TRmax ${ }^{2}+$ RAP).

\section{Statistical analysis}

Statistical analyses were done using SPSS (Statistical Package for the Social Sciences ver. 13, SPSS Inc., Chicago, Illinois, USA) software and Epi info pack program.

Numeric variables were presented as median \pm standard deviation; categorical variables were presented as percentage values. The equality of the data to the normal distribution was assessed with the Shapiro-Wilk test. Since the data was not normally distributed, Mann-Whitney $U$ test, a non-parametric statistical test was used to compare the average values between the groups. Categorical variables were compared using the chi-square test or Fisher's exact chi-square test. For all statistical studies, a $\mathrm{p}$-value $<0.05$ was set to be significant.

\section{Results}

Evaluating basic characteristics, there was no statistically significant difference between the two groups in terms of medications, age, gender distribution, body mass index, and smoking status (Table 1).

\section{Table 1 - Comparison of clinical and biochemical features of patients and controls}

\begin{tabular}{lccc}
\hline & $\begin{array}{c}\text { Patients } \\
(\mathrm{n}=117)\end{array}$ & $\begin{array}{c}\text { Controls } \\
(\mathrm{n}=115)\end{array}$ & P-value \\
\hline age (years) & $61.86 \pm 5.86$ & $61.74 \pm 5.99$ & 0.882 \\
sex (males) $(\mathrm{n}, \%)$ & $55(47 \%)$ & $64(55.7 \%)$ & 0.193 \\
body mass index $\left(\mathrm{kg} / \mathrm{m}^{2}\right)$ & $21.72 \pm 1.96$ & $21.45 \pm 2.12$ & 0.314 \\
creatinin $(\mathrm{mg} / \mathrm{dl})$ & $0.77 \pm 0.21$ & $0.78 \pm 0.19$ & 0.601 \\
smoking & $11(9.6 \%)$ & $14(12 \%)$ & 0.673 \\
leukocyte $\left(10^{\wedge} 3 / \mathrm{\mu l}\right)$ & $7.74 \pm 2.14$ & $7.54 \pm 2.16$ & 0.502 \\
hemoglobin $(\mathrm{g} / \mathrm{dl})$ & $13.80 \pm 1.52$ & $13.89 \pm 1.64$ & 0.676 \\
TSH $(\mathrm{mclU} / \mathrm{ml})$ & $1.66 \pm 1.39$ & $1.49 \pm 1.23$ & 0.322 \\
C-reactive protein $(\mathrm{mg} / \mathrm{l})$ & $7.51 \pm 7.52$ & $6.89 \pm 6.80$ & 0.510 \\
uric acide $(\mathrm{mg} / \mathrm{dl})$ & $5.07 \pm 1.26$ & $5.16 \pm 1.40$ & 0.594 \\
aspartat aminotransferase $(\mathrm{U} / \mathrm{l})$ & $24.38 \pm 7.43$ & $23.93 \pm 6.40$ & 0.625 \\
alanin aminotransferase $(\mathrm{U} / \mathrm{l})$ & $21.49 \pm 14.59$ & $21.41 \pm 8.89$ & 0.961 \\
sodium $(\mathrm{mmol} / \mathrm{l})$ & $139.37 \pm 2.92$ & $139.82 \pm 3.22$ & 0.261 \\
potassium $(\mathrm{mmol} / \mathrm{l})$ & $4.32 \pm 0.41$ & $4.32 \pm 0.35$ & 0.953 \\
calcium $(\mathrm{mg} / \mathrm{dl})$ & $9.52 \pm 0.54$ & $9.6 \pm 0.43$ & 0.964 \\
magnesium $(\mathrm{mg} / \mathrm{dl})$ & $2.00 \pm 0.19$ & $2.02 \pm 0.18$ & 0.564 \\
phosfor $(\mathrm{mg} / \mathrm{dl})$ & $3.31 \pm 0.56$ & $3.33 \pm 0.59$ & 0.912 \\
parathormon $(\mathrm{pg} / \mathrm{ml})$ & $100.42 \pm 60.15$ & $78.25 \pm 44.32$ & 0.002 \\
25-OH vitamin D $(\mathrm{ng} / \mathrm{ml})$ & $6.79 \pm 5.4$ & $18.76 \pm 9.8$ & $<0.001$ \\
\hline
\end{tabular}


Given the main biochemical parameters, the average PTH level of the group of the patients with very low vitamin D was higher than the average PTH level of the control group (100.42 \pm 60.15 and $78.25 \pm 44.32 \mathrm{pg} / \mathrm{ml} ; \mathrm{p}=0.002)$. The average $25-\mathrm{OH}$ vitamin $\mathrm{D}$ level of the patients group was lower than the average $25-\mathrm{OH}$ vitamin $D$ level of the control group $(6.79 \pm 5.4$ and $18.76 \pm 9.8 \mathrm{ng} / \mathrm{ml} ; \mathrm{p}<0.001)$ (Table 1).

The initial conventional echocardiographic parameters of the patients and controls were comparable except average systolic PAP. The average systolic PAP value were higher in the patients groups than controls (36.31 \pm 8.99 and $32.42 \pm 8.06 \mathrm{~mm} \mathrm{Hg} ; \mathrm{p}<0.001)$. There was not statistically significant difference between the groups in terms of the average end-diastolic and end-systolic left ventricular diameter, left ventricular ejection fraction, thicknesses of interventricular septum and posterior wall (Table 2).

Table 2 - Comparison of conventional echocardiographic features of patients and controls

\begin{tabular}{lccc}
\hline & $\begin{array}{c}\text { Patients } \\
(\mathrm{n}=117)\end{array}$ & $\begin{array}{c}\text { Controls } \\
(\mathrm{n}=115)\end{array}$ & P-value \\
\hline LV ejection fraction $(\%)$ & $62.77 \pm 4.46$ & $62.84 \pm 4.41$ & 0.910 \\
LV endsystolic diameter $(\mathrm{mm})$ & $28.46 \pm 3.70$ & $28.51 \pm 4.01$ & 0.919 \\
LV enddiastolic diameter $(\mathrm{mm})$ & $46.72 \pm 3.37$ & $47.09 \pm 3.63$ & 0.424 \\
Interventricular septum $(\mathrm{mm})$ & $10.42 \pm 1.30$ & $10.32 \pm 1.33$ & 0.543 \\
Posterior wall $(\mathrm{mm})$ & $9.51 \pm 1.10$ & $9.53 \pm 1.10$ & 0.856 \\
Left atrium diameter $(\mathrm{mm})$ & $44.79 \pm 5.17$ & $44.46 \pm 6.89$ & 0.099 \\
Right atrium diameter $(\mathrm{mm})$ & $32.42 \pm 8.06$ & $36.09 \pm 6.57$ & 0.158 \\
PASP (mm Hg) & $36.31 \pm 8.99$ & $32.42 \pm 8.06$ & $<0.001$ \\
\hline
\end{tabular}

LV - left ventricular; PASP - pulmonary artery systolic pressure

\section{Discussion}

Recent studies have revealed the functions of vitamin $D$ other than those involved in bone metabolism. It was reported that vitamin $D$ deficiency may be a factor in autoimmune disorders, such as inflammatory bowel disease, rheumatoid arthritis, diabetes, atrial fibrillation, hypertension, heart failure, aortic dilatation, peripheral artery disease, and in several infectious diseases (Holick, 2004; Merlino et al., 2004; Cantorna, 2006; Demir et al., 2012, 2013). Since the discovery of the presence of VDR within many cells, e.g. cardiomyocyte, vascular smooth muscle cell and endothelium, several mechanisms have been proposed to explain the association between vitamin $D$ and cardiovascular disease development (Cardús et al., 2006).

Vitamin D directly leads to VDR and CYP27B1 expressions in the vascular smooth muscle cells and in endothelial cells. Vitamin $D$ ensures blood pressure regulation and prevents cardiac hypertrophy by inhibiting activation of renin; 
hinders the formation of vascular calcification by reducing the productions of MMP2 and MMP9; provides glycemic control; leads to pro-inflammatory cytokine suppression and an increase in IL-10 levels and has cardioprotective effects through its hindering of secondary hyperparathyroidism (Demir et al., 2012).

Considering current evidence indicating the direct effect of vitamin $D$ on the vascular smooth muscle cell, endothelial function and the RAAS system, it is clear that randomized trials of vitamin $D$ replacement and renin and angiotensin inhibition in patients with hypertension and vitamin $D$ deficiency are warranted. Preliminary research has shown an inverse relationship between blood pressure and vitamin D levels, and supplementation appears promising (Holick, 2005; Demir et al., 2013).

In the recent study were found relation between RAAS activities and idiopathic pulmonary arterial hypertension (iPAH) and speculated that chronic inhibition of RAAS by losartan is beneficial in PHT (de Man et al., 2012).

Considering the importance of RAAS in the pathophysiology of PHT and the negative regulatory role of vitamin $D$ for RAAS, we thought that vitamin $D$ deficiency could be related to PHT.

Recently Ulrich et al. (2009) speculated that osteopenia, hyperparatroidism and low vitamin D lewels play an important role PHT pathogenesis. There are some data from small clinical studies that RAAS inhibitors may be beneficial to patients with PHT (de Man et al., 2012).

PTH serum levels were found higher in PHT patient with chronic renal failure and elevated serum PTH predicts impaired survival prognosis in a general aged population and renal failure (Nasri, 2006; Kumbar et al., 2007; Björkman et al., 2008; Agarwal, 2012).

Similarly we found significant correlation between PAP and vitamin D. In our patients, increased PAP correlated positively with PTH and negatively with 25-hydroxyvitamin $D$ levels.

As far as we know, there is no study available in the literature about the association between PHT and vitamin D deficiency. Our study is of importance for this reason.

When the two groups were compared in our study, systolic PAP levels of the patients were significantly higher than the systolic PAP levels of the control group, and the PTH levels of patients groups were significantly higher than the PTH levels of the control persons. Our present data show that vitamin $D$ deficiency may be related to PHT $(p<0.001)$. This result suggests that hyperparathyroidism secondary to vitamin $\mathrm{D}$ deficiency may play a role in higher PAP.

In conclusion, it was found in our study that there might be an association between PHT and vitamin D deficiency. The most important restriction of our study is the limited number of patients. A large-scale research concerning this issue is therefore needed. 


\section{References}

Agarwal, R. (2012) Prevalence, determinants and prognosis of pulmonary hypertension among hemodialysis patients. Nephrol. Dial. Transplant. 27, 3908-3914.

Bischoff-Ferrari, H. A., Giovannucci, E., Willett, W. C., Dietrich, T., Dawson-Hughes, B. (2006) Estimation of optimal serum concentrations of 25-hydroxyvitamin D for multiple health outcomes. Am. J. Clin. Nutr. 84, 18-28.

Björkman, M. P., Sorva, A. J., Tilvis, R. S. (2008) Elevated serum parathyroid hormone predicts impaired survival prognosis in a general aged population. Eur. J. Endocrinol. 158, 749-753.

Cantorna, M. T. (2006) Vitamin D and its role in immunology: multiple sclerosis, and inflammatory boweldisease. Prog. Biophys. Mol. Biol. 92, 60-64.

Cardús, A., Parisi, E., Gallego, C., Aldea, M., Fernández, E., Valdivielso, J. M. (2006) 1,25-dihydroxyvitamin D3 stimulates vascular smooth muscle cell proliferation through a VEGF-mediated pathway. Kidney Int. 69, 1377-1384.

DeLuca, H. F. (2004) Overview of general physiologic features and functions of vitamin D. J. Clin. Nutr. 80, 1689-1696.

de Man, F. S., Tu, L., Handoko, M. L., Rain, S., Ruiter, G., François, C., Schalij, I., Dorfmüller, P., Simonneau, G., Fadel, E., Perros, F., Boonstra, A., Postmus, P. E., van der Velden, J., Vonk-Noordegraaf, A., Humbert, M., Eddahibi, S., Guignabert, C. (2012) Dysregulated renin-angiotensin-aldosterone system contributes to pulmonary arterial hypertension. Am. J. Respir. Crit. Care Med. 186, 780-789.

Demir, M., Uyan, U., Melek, M. (2012) The effects of vitamin D deficiency on the atrial fibrillation. Clin. Appl. Thromb. Hemost. (Epub ahead of print)

Demir, M., Günay, T., Özmen, G., Melek, M. (2013) Relationship between vitamin D deficiency and nondipper hypertension. Clin. Exp. Hypertens. 35, 45-49.

Ginde, A. A., Scragg, R., Schwartz, R. S., Camargo, C. A. Jr. (2009) Prospective study of serum 25-hydroxyvitamin D level, cardiovascular disease mortality, and all-cause mortality in older U.S. adults. J. Am. Geriatr. Soc. 57, 1595-1603.

Holick, M. F. (2004) Sunlight and vitamin D for bone health and prevention of autoimmune diseases, cancer and cardiovascular disease. Am. J. Clin. Nutr. 80, S1678-S1688 (Suppl. 6).

Holick, M. F. (2005) Vitamin D: Important for prevention of osteoporosis, cardiovascular heart disease, type 1 diabetes, autoimmune diseases, and some cancers. South. Med. J. 98, 1024-1027.

Humbert, M., Morrell, N. W., Archer, S. L., Stenmark, K. R., MacLean, M. R., Lang, I. M., Christman, B. W., Weir, E. K., Eickelberg, O., Voelkel, N. F., Rabinovitch, M. (2004) Cellular and molecular pathobiology of pulmonary arterial hypertension. J. Am. Coll. Cardiol. 43, 13S-24S.

Kumbar, L., Fein, P. A., Rafiq, M. A., Borawski, C., Chattopadhyay, J., Avram, M. M. (2007) Pulmonary hypertension in peritoneal dialysis patients. Adv. Perit. Dial. 23, 127-131.

Lang, R. M., Bierig, M., Devereux, R. B., Flachskampf, F. A., Foster, E., Pellikka, P. A., Picard, M. H., Roman, M. J., Seward, J., Shanewise, J., Solomon, S., Spencer, K. T., St. John Sutton, M., Stewart, W.; American Society of Echocardiography's Nomenclature and Standards Committee; Task Force on Chamber Quantification; American College of Cardiology Echocardiography Committee; American Heart Association; European Association of Echocardiography; European Society of Cardiology (2006) Recommendations for chamber quantification. Eur. J. Echocardiogr. 7(2), 79-108.

Merlino, L. A., Curtis, J., Mikuls, T. R., Cerhan, J. R., Criswell, L. A., Saaq, K. G.; lowa Women's Health Study (2004) Vitamin D intake isinversely associated with rheumatoid arthritis: results from the lowa Women's Health Study. Arthritis Rheum. 50, 72-77.

Nasri, H. (2006) Pulmonary artery pressure in association with serum parathormone in maintenance hemodialysis patients. Arch. Med. Sci. 2, 32-35.

Demir M.; Uyan U.; Keçeoçlu S.; Demir C. 
Simonneau, G., Galie, N., Rubin, L. J., Langleben, D., Seeger, W., Domenighetti, G., Gibbs, S., Lebrec, D., Speich, R., Beghetti, M., Rich, S., Fishman, A. (2004) Clinical classification of pulmonary hypertension. J. Am. Coll. Cardiol. 43, 5S-12S.

Ulrich, S., Hersberger, M., Fischler, M., Huber, L. C., Senn, O., Treder, U., Speich, R., Schmid, C. (2009) Bone mineral density and secondary hyperparathyroidism in pulmonary hypertension. Open Respir. Med. J. 3, 53-60. 